الجمعية المصرية للقراعة والمعرفة عضو الجمعية الدولية للمعرفة

مجلة القراعة والمعرفة

العدد 239 الجزء الأول سبتمبر 2021 
الجمعية المصرية للقراعة والمعرفة عضو الجمعية الدولية للمعرفة

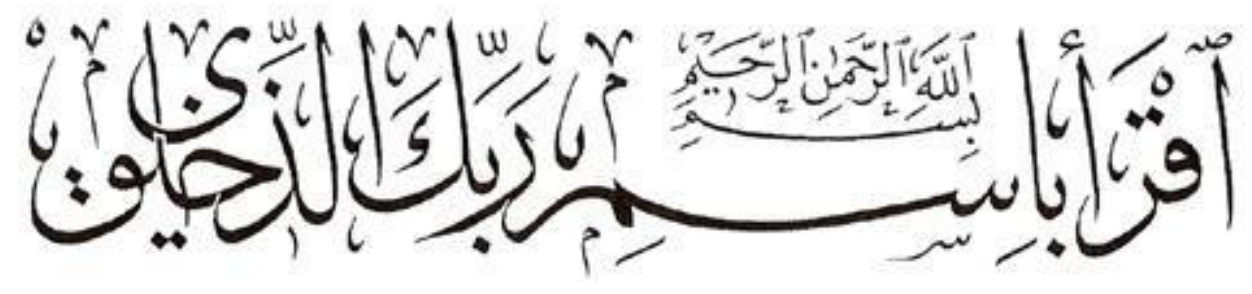

(سورة العلق :آية () (س) () () () 
الجمعية المصرية للقراعة والمعرفة عضو الجمعية الدولية للمعرفة ال

تنشر المجلة إليكترونياً على موقع دار المنظومة للنشر و الرابط الخاص بمجلة القراعة والمعرفة /http://mrk.journals.ekb.eg)

issn (2535- الترقيم الدولى للطباعة : issn الترقيم الدولى الالكترونى (3273 - 2735 ) 
الجمعية المصرية للقراعة والمعرفة عضو الجمعية الدولية للمعرفة المية

مجلة القراعة والمعرفة

\author{
مجلة علمية محكمة \\ تصدر شهرياً \\ رئيس مجلس الإدارة \\ رئيس التحريز

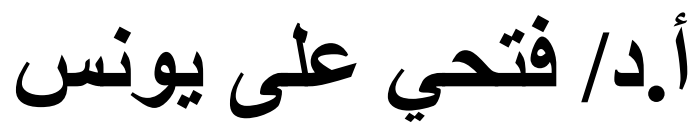 \\ سكرتير التحرير \\ أ.د/ حمحد حمه سبالم
}




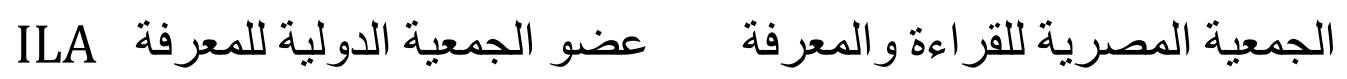

$$
\begin{aligned}
& \text { هيئة التحريز } \\
& \text { أ.د. فتحي على يونس } \\
& \text { رئيس التحرير } \\
& \text { أ.د. عحمد عحمد سالم } \\
& \text { سكرتير التحرير } \\
& \text { أ.د.د. أحمد السعيد الزفتاوي }
\end{aligned}
$$

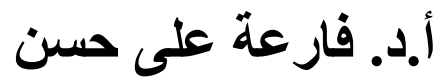

$$
\begin{aligned}
& \text { أ.د. أسماء عحمه غانم عانم }
\end{aligned}
$$

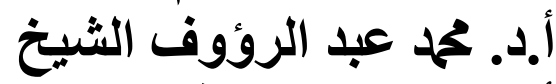

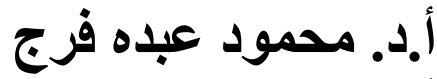

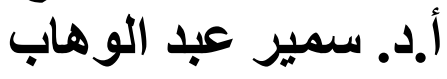

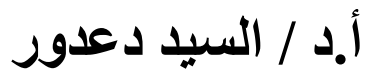

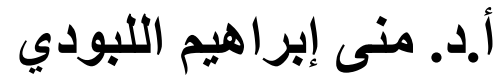

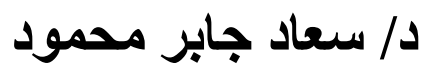

$$
\begin{aligned}
& \text { د / أسماء إبراهيم شريف محيف شيف } \\
& \text { أعضاء التحرير }
\end{aligned}
$$


ILA الجمعية المصرية للقراعة والمعرفة عضو الجمعية الدولية للمعرفة

\section{مستشنارو التحريز}

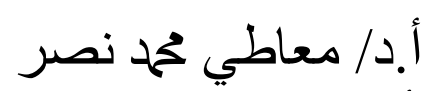

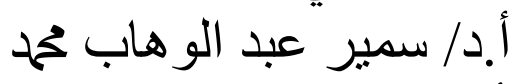

أ.د/ مصطفى رسلان رسلان

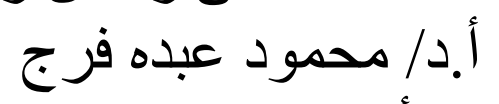

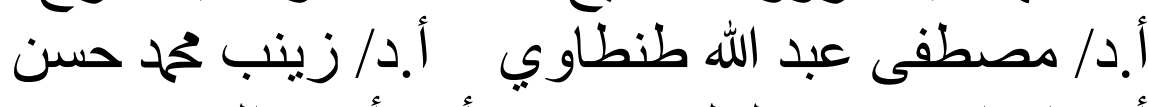

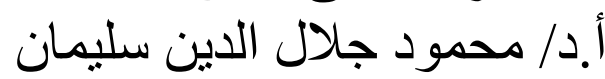

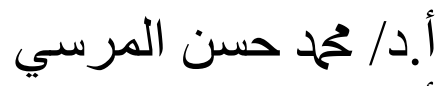

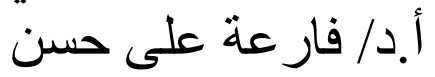

أ.د/ محمد عبد الرؤوف مهود الثيخ الثيخ

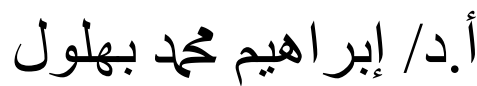

$$
\text { أ.د/ السيد دعدور أحد الدوري }
$$

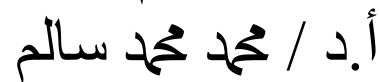

أ.د/ منى اللبودى لدئ داعور

أ.د/ يحيى عطية الإدية

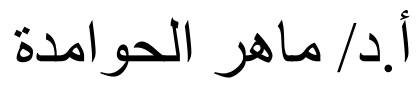

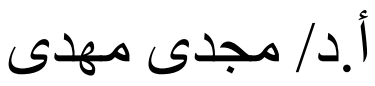

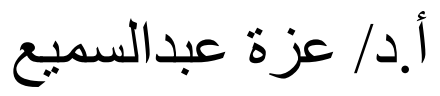

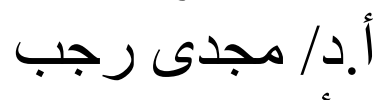

أ.د / فايزة مجدم عبدالسلام

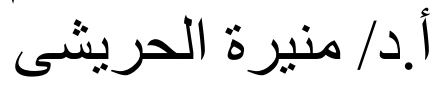

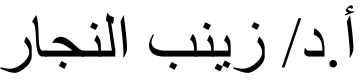

أ.د/ عبدالرحمن زلبن الأحمد

أ.د/ زينب خليفة

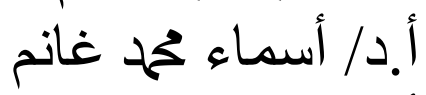

أ.د/ حنان مدبولى إديلى

أ.د/ صسالح النصار مدئ

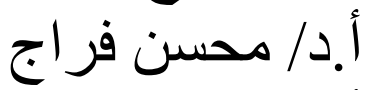

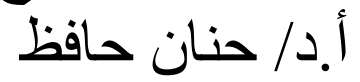

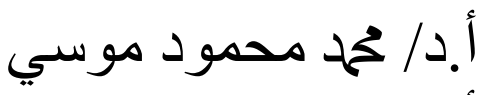

أ.د / فايزة الحسينى ماتح

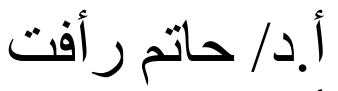

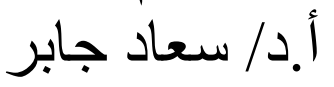

أ.د/ عبدالله الكندري

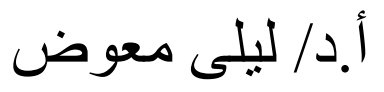


الجمعية المصرية للقراعة والمعرفة عضو الجمعية الدولية للمعرفة ال

\section{نشرت جريدة الأهرام بتاريخ 2001/6/7}

\section{تهنئة}

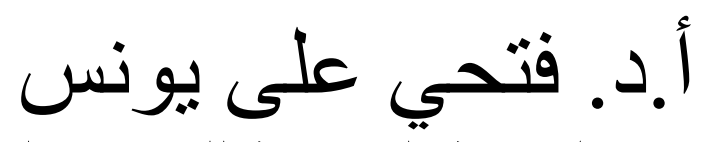

رئيس مجلس إدارة الجمعية المصرية للقر اعة و المعرفة لحصول

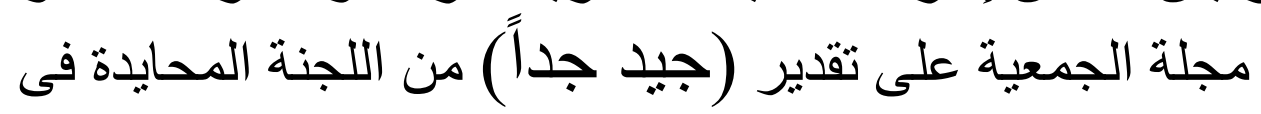
تقويمها الجديد للمجلات العلمية بمجال المناهج وطرق التدريس 
الجمعية المصرية للقراعة والمعرفة عضو الجمعية الدولية للمعرفة ال

تششر المجلة إليكترونياً على موقع دار المنظومة للثشر

\author{
والرابط الخاص بمجلة القراءة والمعرفة
}

\title{
/http://mrk.journals.ekb.eg)
}

\section{مكتبة الإسكندرية}

تختار مجلة القراعة والمعرفة إحدى الدوريات العربية المنتقاة المتخصصة، والمطلوب تزويد مكتبة الإسكندرية

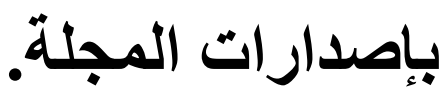


الجمعية المصرية للقراءة والمعرفة عضو الجمعية الدولية للمعرفة

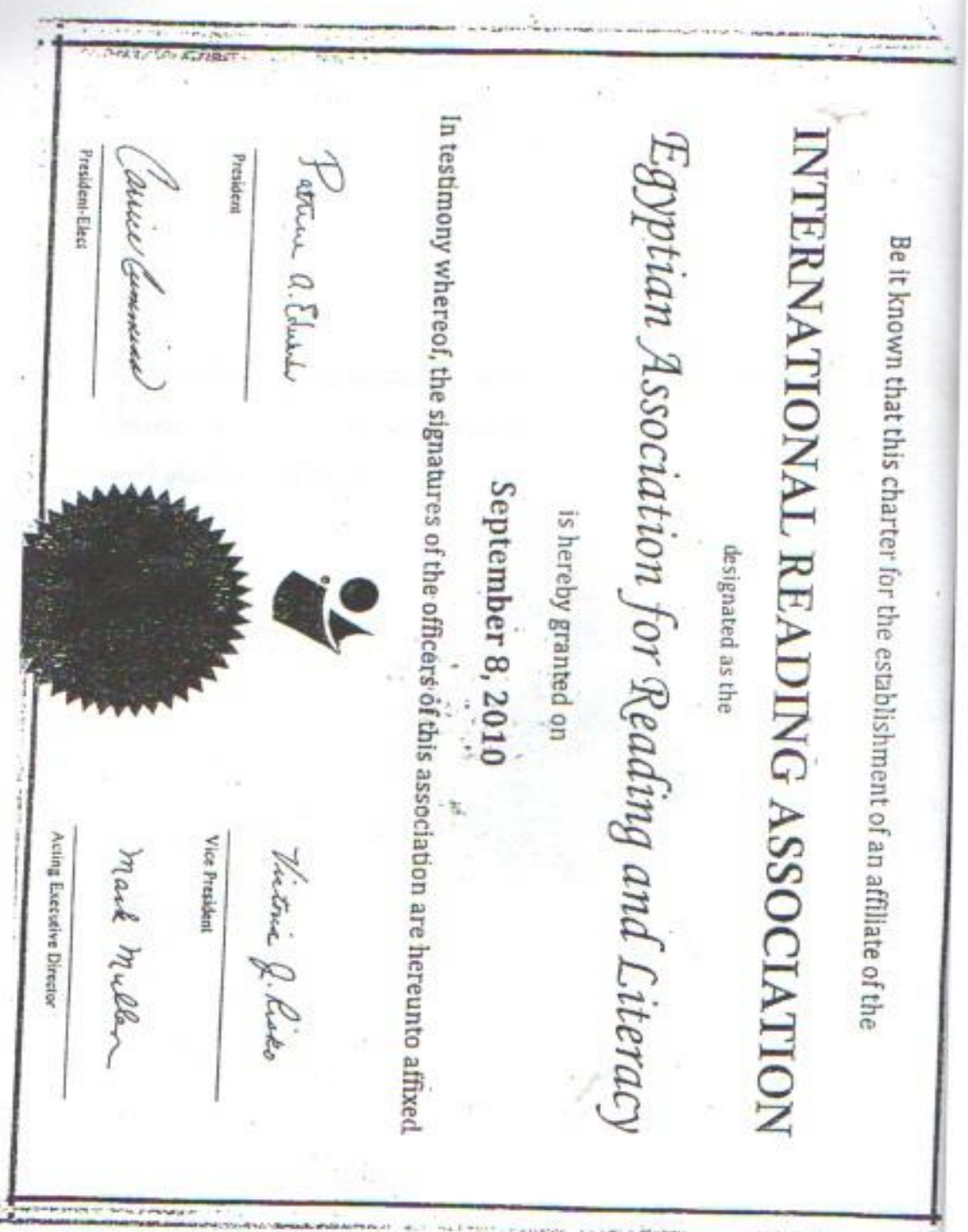


الجمعية المصرية للقراءة والمعرفة عضو الجمعية الدولية للمعرفة

ليكن معلوماً أن جمعيتكم (الجمعية المصرية للقر اعة والمعرفة) قد أصبحت فرعا معترفاً به من (الجمعية الدولية للقراءة) بتاريخ 8 سبتمبر 2010 وتم أعتماد ذلك من.

Patrene a. Edued

President

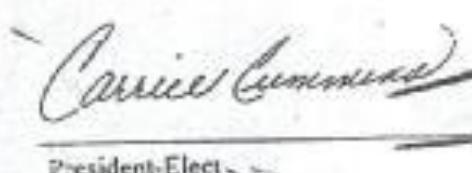

Pesident-Elect -
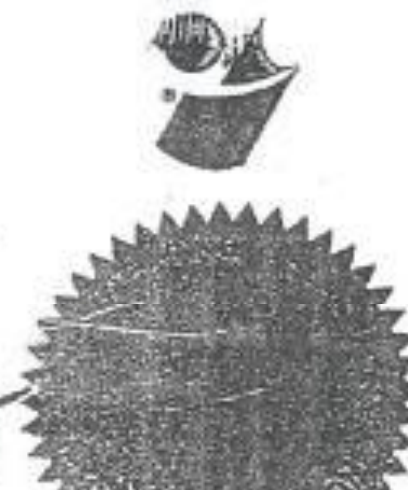

Dintrie Q. listo

Vice President

mack mullan

Acting Execunive Director 
ILA الجمعية المصرية للقر اعة و المعرفة عضو الجمعية الدولية للمعرفة

Kingdon of Sowdi Aribio

Ministry of Higher Education

King Saud University

Arabic Language Institute

Date

Fint
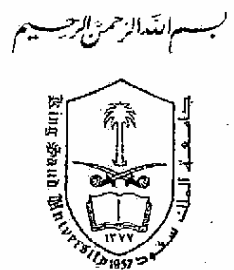

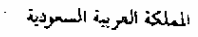

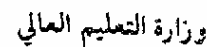

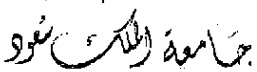

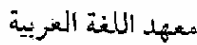

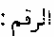

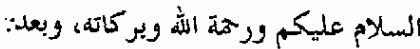

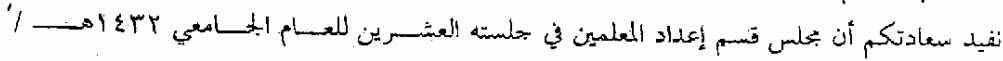

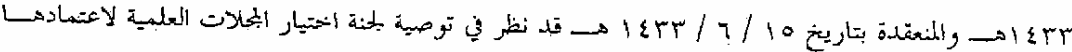

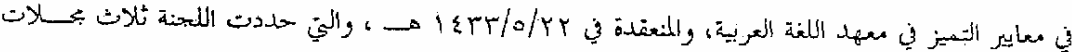

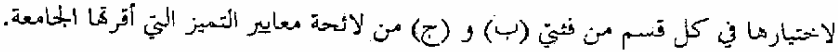

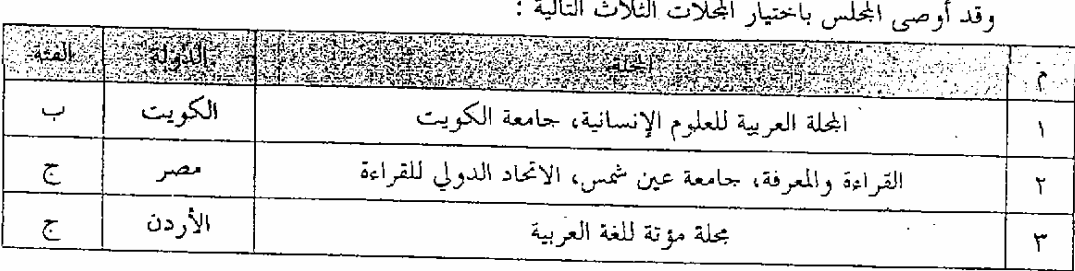

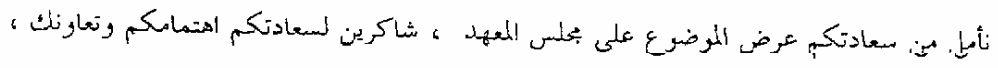

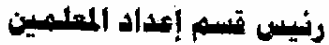

وتقبلوا فائز تمياتي وخالص تمثيري

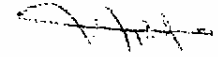

ه. عبد الرهمن بن إلبراهيم الفوزان

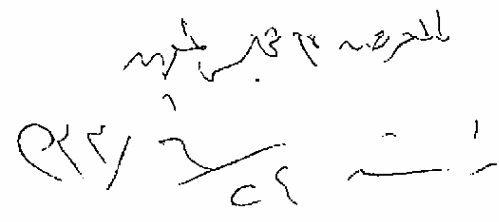


ILA الجمعية المصرية للقر اءة والمعرفة عضو الجمعية الدولية للمعرفة

\section{التعريف بالجمعية المصرية للقراعة والمعرفة}

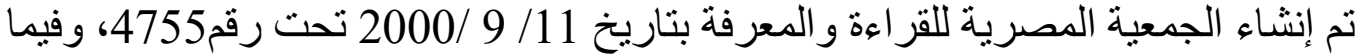

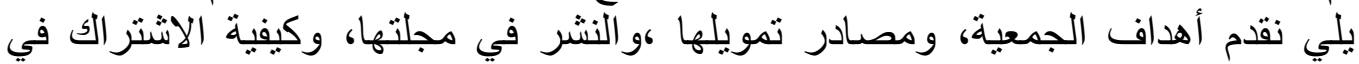

\section{أولاًً : الأهداف ومجالات الأنشطة}

نشر الوعي القرائي لاى الفئات العمرية المختلفة انطلاقاً من مشروع القراءة التأكيد على دور القر اءة في تنمية المستويات المعرفية المختلفة .

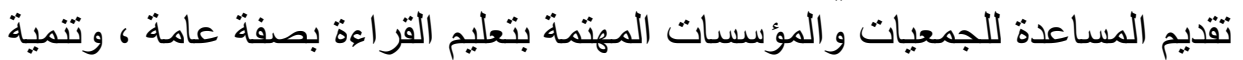

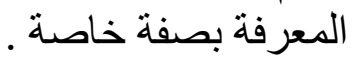
تتمية الاتجاه نحو القراءة، وتحصيل المعرفة باعتبار ذلك المدخل الوحيد و الأساسي للقرن القادم التاه تقديم بعض الخدمات التعليمية ، والأساليب في مجال القراءة و المعرفة بصفة خاصة في المؤسسات التربوية و التعليمية .

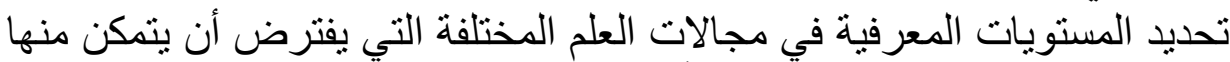

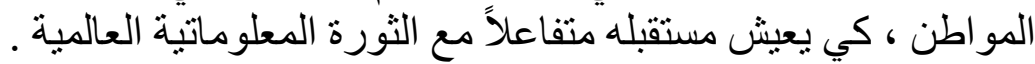

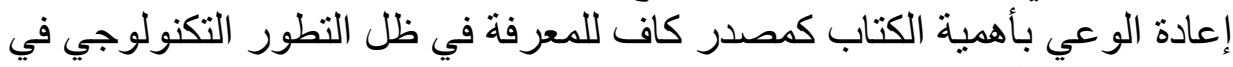

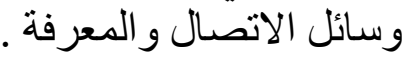

تبادل الخبرة مع الجهات، والهيئات، و المؤسسات المعنية بالقر اعة وتنمية المعرفة.

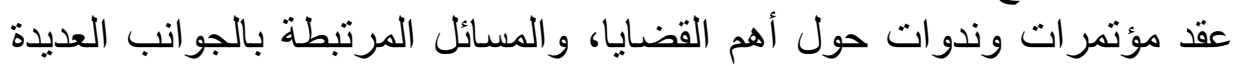
للقز اعة وتنمية المعرفة عقد دورات تدريبية من أجل تنمية الوعي بأهمية القراءة ، وتحصيل المعرفية الهرفة

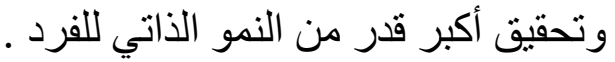

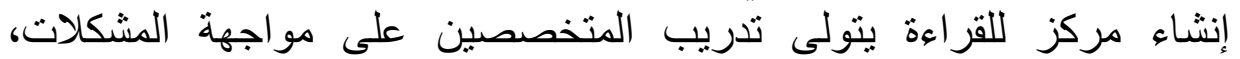
و الصعوبات التى يعانى منها التلاميذ، و الطلاب في تعلم القراءة في مر احل التعليم المختلفة . نطاق عمل الجمعية الجغر افي هو جميع أنحاء جمهورية مصر العربية. 


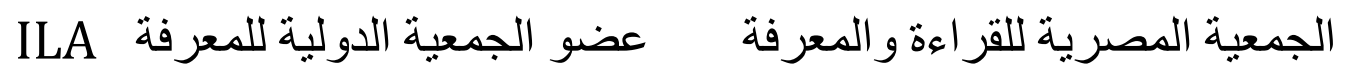

\section{ثانيا : موارد الجمعية تثكون من}

(1) الشتراكات الأعضاء السنوية وهى عبارة عن مبلغ قدره ستون جنيهاً مصرياً.

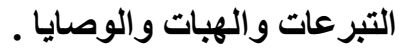

الإعانات الحكومية .

(4) الموارد الأخرى التي يوافق عليها مجلس الإدارة التى تتمشى مع اللوائح المنظمة لعمل

\section{ثالثا : النشر في مجلة الجمعية}

تصدر الجمعية مجلة علمية محكمة تصدر شهرياً باسم مجلة القراءة والمعرفة،

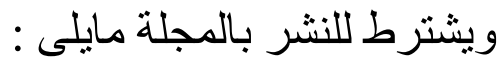

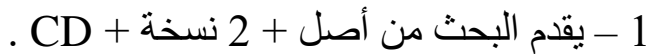

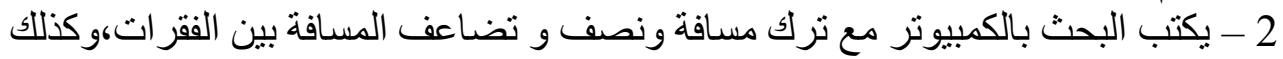
العناوين ، ويكتب متن البحث ببنط MONOTYP KOUFI 16 و العناوين الجانبية بخط TIMES NEW ROMAN

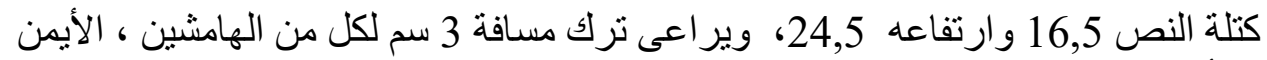

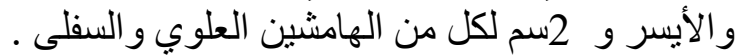

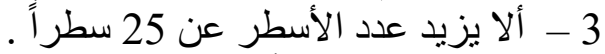

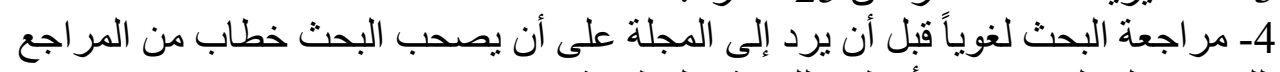

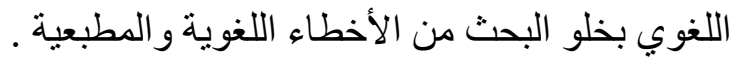

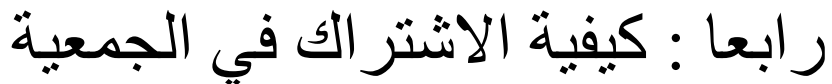

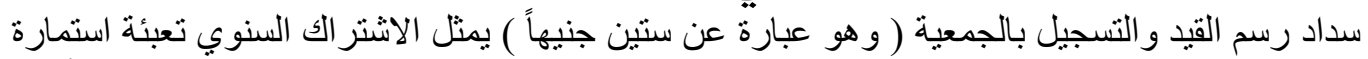

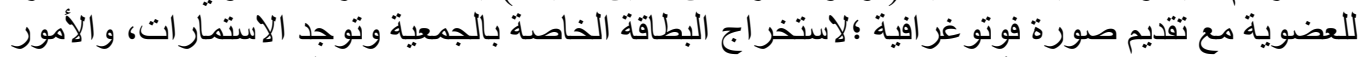
الخاصة بالاشتر اكات مع الأستاذ الدكتور / فتحي على يونس رئيس تحرير المجلة .

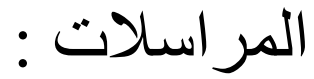

المقر المؤقت : قسم المناهج وطرق التدريس

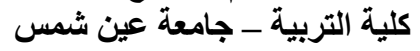

روكسى - مصر الجديدة - القاهرة . 
ILA الجمعية المصرية للقر اءة والمعرفة عضو الجمعية الدولية للمعرفة

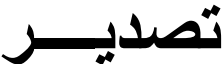

يسر مجلس إدارة الجمعية المصرية للقراءة والمعرفة أن تقدم لقر ائها الأعز اء العدد (239) الجزء الأول سبتمبر 2021 متضمناً الأبحاث التالية:-

\begin{tabular}{|c|c|c|c|}
\hline الصفحة & اسم الباحث & عنوان البحث & p \\
\hline 15 & لد / منال إبراهيم عبد الله مديني & 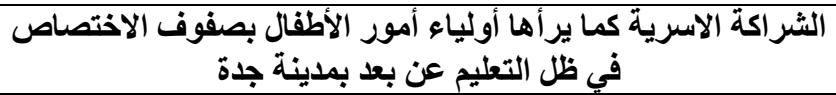 & 1 \\
\hline 85 & د/ نجاء بن طلق بن نجاء العتيبي & 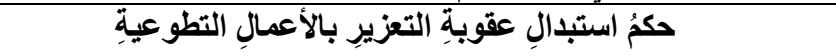 & 2 \\
\hline 123 & 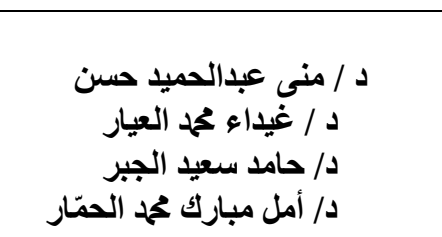 & 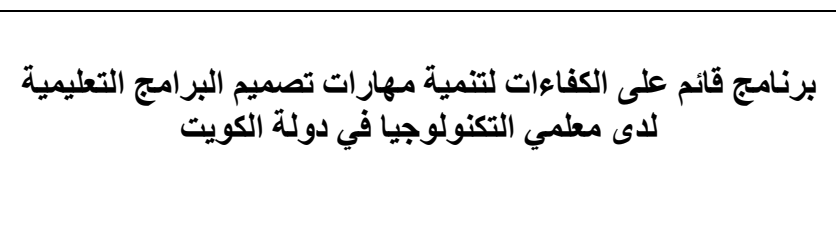 & 3 \\
\hline 155 & د/ مها بنت إبراهيم الكلثم & في محتوى كتب الدراسات الاجتماعية والمواطنة للمرحلة الابتدائية & 4 \\
\hline 197 & أ / مازن مجحود عوض الزهراني & درجة امتلاك وممارسة معلمي العوقة السمعي لمهارات التواصل & 5 \\
\hline 237 & أ / خديجة محفوظ الثنقيطي & المنهج الاستبدالي في كتاب نتائج الفكر في النحو للسهيلي & 6 \\
\hline 263 & أ / أ هيفا سويعد سعيد العوفي & أثر اختلاف مجالات الموهبة للموهوبين السعوديين على التحصيل & 7 \\
\hline 289 & أ / ابتسام بنت سالم الغامدى & الخصائص الطبيعية لتربة المدرجات الزراعية بمنطقة الباحة & 8 \\
\hline 325 & أ / خالد عبده محسن الجميلي & 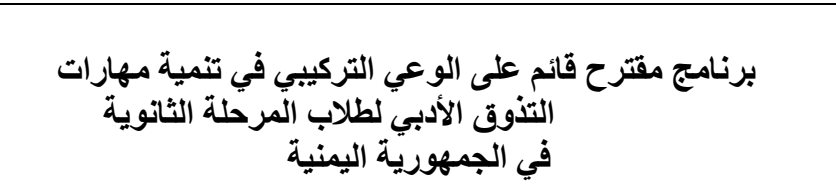 & 9 \\
\hline
\end{tabular}




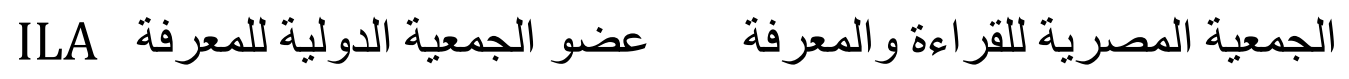

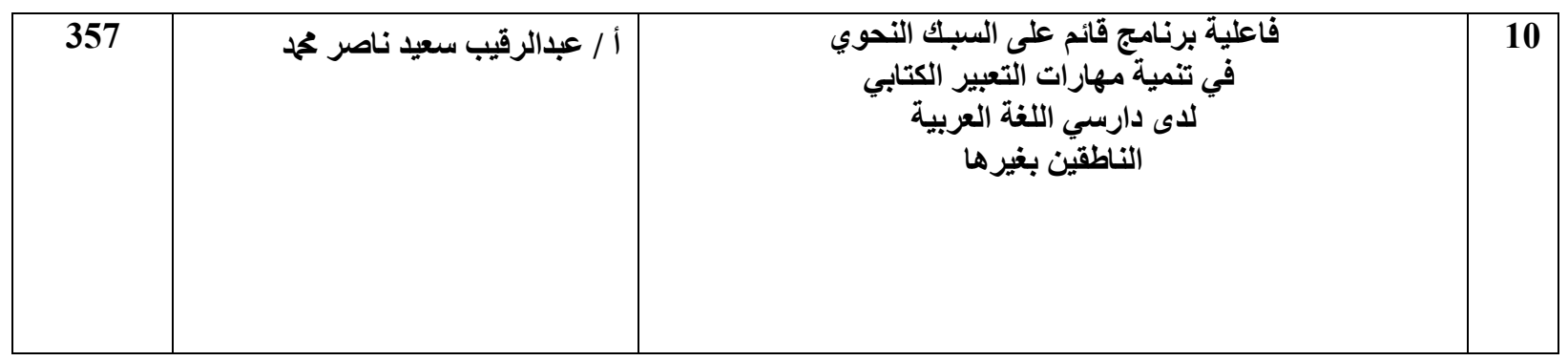

ونأمل أن يفيد محتوى هذا العدد العاملين والباحثين في مجال القراعة والمعرفة في مصر والوطن العربي، كما يسعد أسرة تحرير المجلة أن تتلقى أية مقترحات تسهم في تطويرها، كما نرجوا الالتزام بقواعد النشر المدونة بالمجلة رئيس تحرير والله الموفق

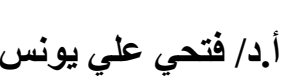
سكرتير المجلة أ.د/ عحم محمد سالم 